\title{
Geographical distribution of gastrointestinal cancers in India with special reference to causation
}

\author{
S. L. MALHOTRA \\ From the Medical Department, Western Railway, Bombay, India
}

EDITORIAL COMMENT These important observations suggest that is it the irritation from the highly alkaline lime, and not the tobacco leaf, on the betel nut in the chewing quid, which predisposes towards malignant changes in the buccal mucosa.

Interesting studies on the distribution of cancer of the stomach and cancer of the liver are recorded and it is suggested that these differences may possibly be associated with variations in the pattern of diet and eating.

Important and interesting differences in the incidence of gastrointestinal cancers exist not only between different countries but even within a single country (Steiner, 1954; Paymaster, 1964; World Organization of Gastro-enterology, 1964;:Segi and Kurihara, 1964). Moreover, the incidence among migrant populations is, in general, intermediate between that found in their original homeland and that in the country to which they have migrated (Haenszel, 1961). This has formed the basis for the hypothesis that these tumours may be caused by environmental factors; but, as recently commented in the British Medical Journal (1966): 'so far attempts to associate cancer of the oesophagus, stomach, or colon with particular environmental factors have provided only weak associations or given disappointingly inconclusive results'.

Gastrointestinal cancers are the commonest malignant tumours among Indians and formed as high a percentage as 34.9 of all malignancies (Paymaster, 1964). Moreover, striking geographical variations exist in the incidence of these cancers in the various parts of the country. The present paper attempts to study the geographical distribution of gastrointestinal cancers in India in a population of known composition, with the principal objective of defining the geographical differences in their incidence in the various parts of the country and exploring possible clues to their causation.

\section{METHODS AND MATERIAL}

The clinical data included in this enquiry are derived from the official diagnostic index (W.H.O. International Statistical Classification, 1957) of all the railway hospitals in the country. There are eight zonal railways in India which run a group of 86 railway hospitals, exclusively for the benefit of the railway staff in different geographical regions of the country. These hospitals provide services which are comprehensive and include all specialities. For the treatment of cancer, the railways have also provided extra facilities by arrangement with various centres which deal exclusively with cancer patients. Information from two zonal railways, namely, the Eastern and the Northeast Frontier Railways, comprising 20 hospitals, could not be studied due to certain technical difficulties. Thus the available data are broadly representative of the whole country except the extreme eastern regions, comprising Assam and parts of North Bengal.

THE POPULATION AT RISK The study concerns 1.03 million railway employees between the ages of 18 and 55 years serving on the six zonal railways (excluding eastern and northeast frontier zones) in different parts of the country, and 1.02 million adult dependent family members, namely, the wives and widowed mothers of the employees. Children have been excluded from this population, chiefly because there were only two cases of these cancers among them, one of cheek and the other of pancreas. The age-wise distribution of this population is given in Table $\mathrm{I}$. Because of uniform administrative patterns and policies of recruitment, promotion, and superannuation on the various zonal railways, the compositions of the population on the various zones are comparable with each other with regard to age, sex, and their relative distribution in different occupations and social classes. Thus, although this population cannot claim to give an accurate picture of the incidence-rates of these cancers in the general population in the country because of the age structure of the employees being from 18 to 55 years, for the sake of geographical comparisons, it has several advantages over the general population. 


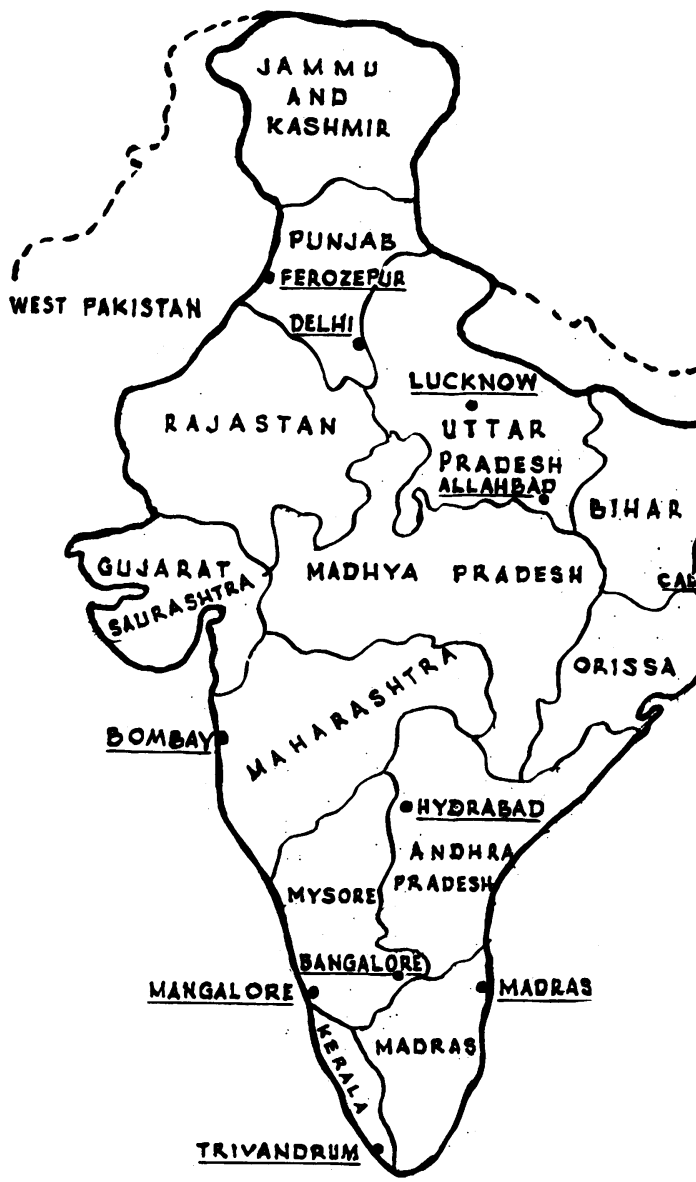

TABLE I

NUMBER EXPOSED TO RISK IN EACH AGE GROUP ${ }^{1}$

\begin{tabular}{l} 
Ages in Year \\
\hline Under $17^{2}$ \\
$18-24$ \\
$25-34$ \\
$35-44$ \\
$45-54$ \\
$55^{3}$ \\
$56-64^{4}$ \\
All ages
\end{tabular}

Males

Females

1 Total population at the beginning of each year between 1 January 1960 and 31 December $1964 \div 5$.

2 Persons under 17 are not included in this group as gastrointestinal cancers were uncommon in this age group, there being only two cases, one of pancreas and the other of the cheek.

3 The age of superannuation was raised by the Ministry of Railways from 55 years to 58 years with effect from 1963 .

4 The females in age group 56 to 64 years are chiefly widowed mothers of the railway employees.
FIG. 1. Diagrammatic map of India.
For example, its exact constitution is precisely known and is comparable with respect to age, sex, and social status in the different zones; each railway hospital serves a known population so that the number of cases diagnosed can be related to the population at risk; no diagnosed case can remain unrecorded as railway employees have to obtain a certificate in case of illness which is entered in the diagnostic index; and most important of all, the Ministry of Railways provides special facilities for the diagnosis and treatment of all cancers both at the railway hospitals and by arrangement with specialist hospitals doing exclusively cancer work at a number of centres in the country. It is, therefore, believed that in this study all cases of gastrointestinal cancers among railway employees have been recorded.

ASCERTAINMENT OF CASES The diagnostic index of all the railway hospitals, included in this study, was searched for the period 1 January 1960 to 31 December 1964 for patients bearing any of the following diagnoses: cancer of the lip, tongue, salivary gland, mouth, cheek, tonsil, pharynx, oesophagus, stomach, small intestine, large intestine, rectum, liver (hepatoma), gall bladder, liver secondaries, pancreas, or peritoneum. This provided the provisional lists of patients diagnosed of these tumours. Through the courtesy and generosity of the chief medical officers of the zonal railways, the records of all patients admitted to this provisional list were then studied and scrutinized with regard to age, sex, social class, residence, and the validity of the final diagnosis.

Only those patients in whom a diagnosis had been established by a histopathological examination or by surgical operation (definite diagnosis), or by clinical examination by a cancer specialist and radiological 
investigation (probable diagnosis) were included in the list of accepted cases. All these cases had also been referred to special cancer centres and seen by a cancer specialist and treated with either surgery, radiotherapy, or palliative procedures.

\section{TABLE II}

NUMBER OF CASES OF ALL CANCERS OF GASTROINTESTINAL TRACT OCCURRING BETWEEN 1 JANUARY 1960 AND 31 DECEMBER 1964

\begin{tabular}{|c|c|c|c|c|}
\hline \multirow[t]{2}{*}{ Age in Years } & \multicolumn{2}{|c|}{ Males } & \multicolumn{2}{|c|}{ Females } \\
\hline & No. & $\begin{array}{l}\text { Percentage } \\
\text { of Total }\end{array}$ & No. & $\begin{array}{l}\text { Percentage } \\
\text { of Total }\end{array}$ \\
\hline $\begin{array}{l}\text { Under } 14 \\
15-24 \\
25-34 \\
35-44 \\
45-54 \\
55 \\
56 \text { and over } \\
\text { All ages }\end{array}$ & $\begin{array}{r}- \\
6 \\
35 \\
126 \\
177 \\
9 \\
10 \\
363\end{array}$ & $\begin{array}{r}- \\
1 \cdot 3 \\
7 \cdot 4 \\
26 \cdot 8 \\
37 \cdot 7 \\
1 \cdot 9 \\
2 \cdot 1 \\
77 \cdot 2\end{array}$ & $\begin{array}{r}2 \\
1 \\
21 \\
35 \\
15 \\
3 \\
30 \\
107\end{array}$ & $\begin{array}{r}0.4 \\
0.2 \\
4 \cdot 5 \\
7 \cdot 5 \\
3 \cdot 2 \\
0.6 \\
6.4 \\
22 \cdot 8\end{array}$ \\
\hline
\end{tabular}
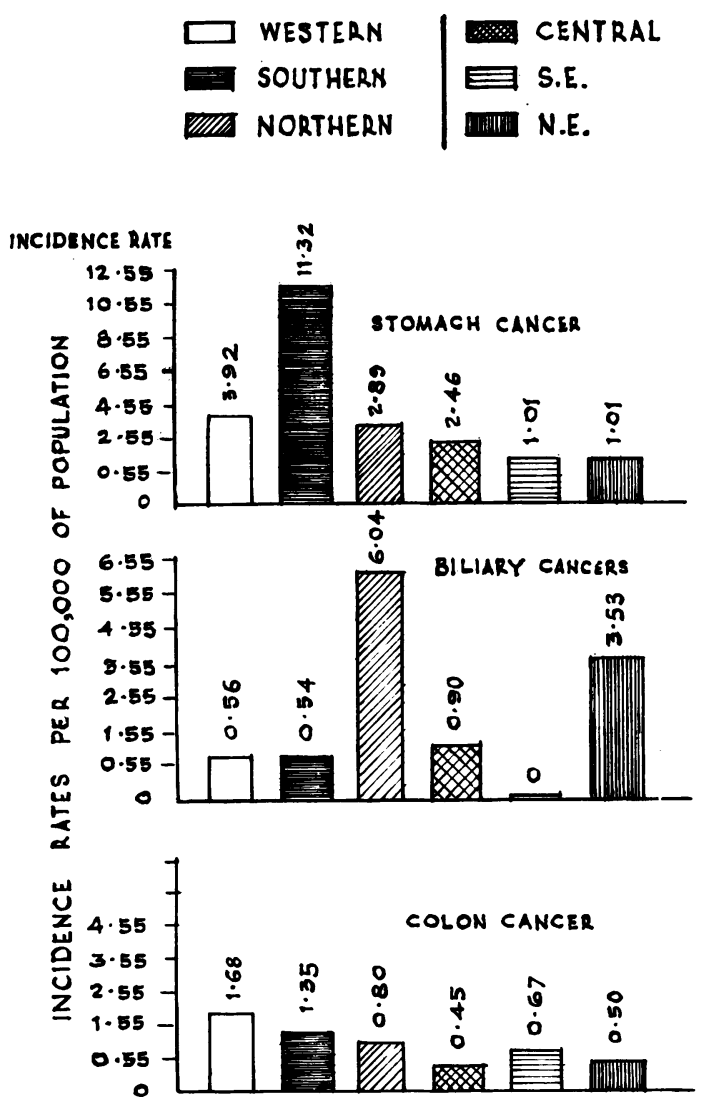

FIG. 2. The observed frequency of different cancers in this series.

\section{RESULTS}

A total of 470 proved gastrointestinal cancers was admitted to the list of accepted cases (Table II and Fig. 2). Their geographical distribution on the various zonal railways is shown in Table III. Table IV shows the age and sex-wise distribution rates of the various cancers, and Table $\mathrm{V}$ the agewise distribution rates of these cancers in the different geographical regions. There were 33 cases in women above the age of 55 years, and these were mainly among the widowed mothers of the railway employees. Although the number of widowed mothers at risk within this age group is not precisely known, our sample surveys carried out during the national smallpox eradication scheme showed that widowed mothers constituted $40 \%$ of the number of employees. The incidence rates among women within this age group are, therefore, based on this premise.

CANCERS OF THE BUCCAL CAVITY Of a total of $\mathbf{4 7 0}$ cases, 183 were related to the buccal cavity (International Statistical Classifications 140-148), constituting $39 \%$ of all gastrointestinal cancers in this series (Fig. 2). The disease was four times more prevalent among men than among women; the tongue was involved almost twice as frequently as the cheek while the lips were affected the least, there being only six cases of cancer of the lip. There were 15 cases of cancer of the pharynx, contributing $3.2 \%$ of all gastrointestinal cancers. This cancer is known to be very common in Assam but unfortunately the information concerning Assam, in this study, was not available to us.

Although the incidence of these cancers is relatively less in the south of India compared with the northern and eastern parts of the country (Table III), in the north itself there are interesting differences between the Punjab on the one hand, and Rajasthan and Uttar Pradesh (U.P.), on the other, the highest incidence being from U.P. and Rajasthan and the lowest from the Punjab. A detailed analysis of the cases on the Southern Railway showed that those affected were mostly people of the lower income group and social class belonging to the regions of Andhra and Kerala. The age distribution of these cancers (Table II) showed that the peak incidence was between the ages of 35 and 55 years, the incidence being relatively less in the younger age groups.

CANCER OF THE OESOPHAGUS Cancer of the oesophagus was the third commonest gastrointestinal cancer in this study and accounted for 53 cases (11\%) of a total of 470 cases (Fig. 2, Table III). It was nearly seven times more common in men as 
TABLE III ${ }^{1,2}$

GEOGRAPHICAL DISTRIBUTION OF THE GASTROINTESTINAL CANCERS AND THE QUADRENNIAL INCIDENCE RATES FOR THE PERIOD 1 JANUARY 1960 TO 31 DECEMBER 1964 IN RAILWAY POPULATIONS (ADULTS ONLY) IN DIFFERENT PARTS OF INDIA

\begin{tabular}{|c|c|c|c|c|c|c|c|c|c|c|c|c|}
\hline \multirow{5}{*}{ Cancer } & \multicolumn{8}{|c|}{ Population } & & & & \\
\hline & \multirow{2}{*}{\multicolumn{4}{|c|}{$\frac{\text { Western }}{357,069}$}} & \multirow{2}{*}{\multicolumn{4}{|c|}{$\frac{\text { Southern }}{370,955}$}} & \\
\hline & & & & & & & & & \multicolumn{4}{|c|}{$\frac{\text { Northern }}{380,873}$} \\
\hline & \multicolumn{3}{|c|}{ No. of Cases } & \multirow{2}{*}{$\begin{array}{l}\text { Incidence } \\
\text { per } 100,000\end{array}$} & \multicolumn{3}{|c|}{ No. of Cases } & \multirow{2}{*}{$\begin{array}{l}\text { Incidence } \\
\text { per } 100,000\end{array}$} & \multicolumn{3}{|c|}{ No. of Cases } & \multirow{2}{*}{$\begin{array}{l}\text { Incidence } \\
\text { per } 100,000\end{array}$} \\
\hline & $M$ & $\boldsymbol{F}$ & Total & & $\boldsymbol{M}$ & $F$ & Total & & $\boldsymbol{M}$ & $\boldsymbol{F}$ & Total & \\
\hline Lip (140) & 0 & 1 & 1 & $0 \cdot 28$ & - & - & & - & - & - & & - \\
\hline Tongue (141) & 27 & 2 & 29 & $8 \cdot 12$ & 5 & 1 & 6 & 1.62 & 10 & 7 & 17 & $4 \cdot 46$ \\
\hline Salivary gland (142) & - & 一 & & - & - & - & & - & 1 & $\mathbf{0}$ & 1 & 0.26 \\
\hline Mouth (143) & $\mathbf{0}$ & 1 & 1 & 0.28 & 3 & 0 & 3 & 0.81 & 3 & 1 & 4 & 1.05 \\
\hline Cheek (144) & - & 一 & & - & 4 & 4 & 8 & $2 \cdot 16$ & 11 & 6 & 17 & $4 \cdot 46$ \\
\hline Tonsil (145) & 一 & - & & - & 1 & $\mathbf{0}$ & 1 & 0.27 & 5 & $\mathbf{0}$ & 5 & $1 \cdot 31$ \\
\hline Pharynx (148) & - & - & & - & 2 & $\mathbf{0}$ & 2 & 0.54 & 4 & $\mathbf{0}$ & 4 & 1.05 \\
\hline Oesophagus (150) & 15 & 1 & 16 & 4.48 & 12 & 1 & 13 & 3.50 & 5 & 4 & 9 & $2 \cdot 36$ \\
\hline Stomach (151) & 11 & 3 & 14 & 3.92 & 40 & 2 & 42 & $11 \cdot 32$ & 7 & 4 & 11 & $2 \cdot 89$ \\
\hline Large intestine (153) & 4 & 2 & 6 & 1.68 & 4 & 1 & 5 & $1 \cdot 35$ & $\mathbf{0}$ & 3 & 3 & 0.80 \\
\hline Rectum (154) & 6 & 3 & 9 & $2 \cdot 52$ & 6 & 1 & 7 & 1.89 & 6 & 2 & 8 & $2 \cdot 10$ \\
\hline Liver (155) & 2 & 0 & 2 & 0.56 & 2 & $\mathbf{0}$ & 2 & 0.54 & 8 & 5 & 13 & 3.42 \\
\hline Gall bladder (155-1) & - & 一 & 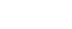 & - & - & - & & - & 3 & 7 & 10 & $2 \cdot 62$ \\
\hline Liver secondaries (156) & $\mathbf{0}$ & 2 & 2 & 0.56 & - & 一 & & - & $\mathbf{0}$ & 2 & 2 & 0.53 \\
\hline Pancreas (157) & - & - & & - & 3 & 1 & 4 & $1 \cdot 07$ & - & - & & - \\
\hline Peritoneum (158) & 一 & - & & - & - & - & & - & 1 & $\mathbf{0}$ & 1 & 0.26 \\
\hline Unclassified (159) & - & 一 & & - & 7 & 1 & 8 & $2 \cdot 16$ & 3 & 1 & 4 & 1.05 \\
\hline Grand Total & 65 & 15 & 80 & $22 \cdot 40$ & 90 & 12 & 102 & $27 \cdot 50$ & 67 & 42 & 109 & $28 \cdot 62$ \\
\hline
\end{tabular}

1 The data for the central railway are incomplete as one of 11 hospitals of central railway had still not responded at the time of writing. The data from two other zonal railways, i.e., the eastern and the northeast frontier, have not been included for the same reason.

2 Population at risk is composed of railway employees and their wives but does not include children.

compared with women. Western and southern regions together accounted for $55 \%$ of all the oesophageal cancers in this study, while the disease was less common in the eastern parts of the subcontinent.

CANCER OF THE STOMACH Gastric cancer constituted $18 \%$ of all gastrointestinal cancers, being the second commonest gastrointestinal cancer in the present series, 83 cases of a total of 470 being of this site. There were four times as many cases in the south as in the north (Fig. 2 and Table III). Of the 11 cases on the northern railway, only one was from the Punjab (Ferozepur and Delhi Divisional Hospitals: population, 17,988) and he too was a migrant from U.P., whilst the remaining 10 were from other parts of the country served by the northern railway, such as Allahabad, Lucknow, Jodhpur, Bikaner, and Moradabad (population, $1,74,012$ employees). The sex distribution showed a remarkable preponderance for males, the male :female ratio being 7:1 in the series as a whole, but 20:1 in South India. In the Bombay area of the western railway, of six cases of cancer of the stomach, three were among women, a sex ratio of $1: 1$. The disease was most prominent in the age group 35 to 55 years in south India and 45 to 55 years in the north, which indicates that the age of maximum incidence is a decade earlier among the south Indians compared with the north Indians.

CANCERS OF THE LIVER AND THE GALL BLADDER Eight per cent of gastrointestinal cancers in this series were due to primary hepatoma or cancer of the gall bladder (International Statistical Classification 155 and $155: 1$ ), there being 26 cases of hepatoma and 12 of gall bladder cancer. Here the geographical distribution was just the reverse of that for gastric cancers, the malignancies of the liver and gall bladder being 12 times more common in the north of India compared with the south. Thus, the incidence rates of these cancers were 6 per 100,000 of population on the northern railway in contrast to 0.5 per 100,000 on the southern zone (Table III). Whilst hepatoma was one and a half times more common in men, cancer of the gall bladder was three times more frequent in women as compared with men.

CANCER OF THE RECTUM AND COLON No significant geographical differences in incidence of cancer of the rectum, which is a fairly common malignancy, have been observed although cancer of the colon seems to be far less common in the north of the country as compared with the south. 
TABLE III 1,2 continued

GEOGRAPHICAL DISTRIBUTION OF THE GASTROINTESTINAL CANCERS AND THE QUADRENNIAL INCIDENCE RATES FOR THE PERIOD 1 JANUARY 1960 TO 31 DECEMBER 1964 IN RAILWAY POPULATIONS (ADULTS ONLY) IN DIFFERENT PARTS OF INDIA

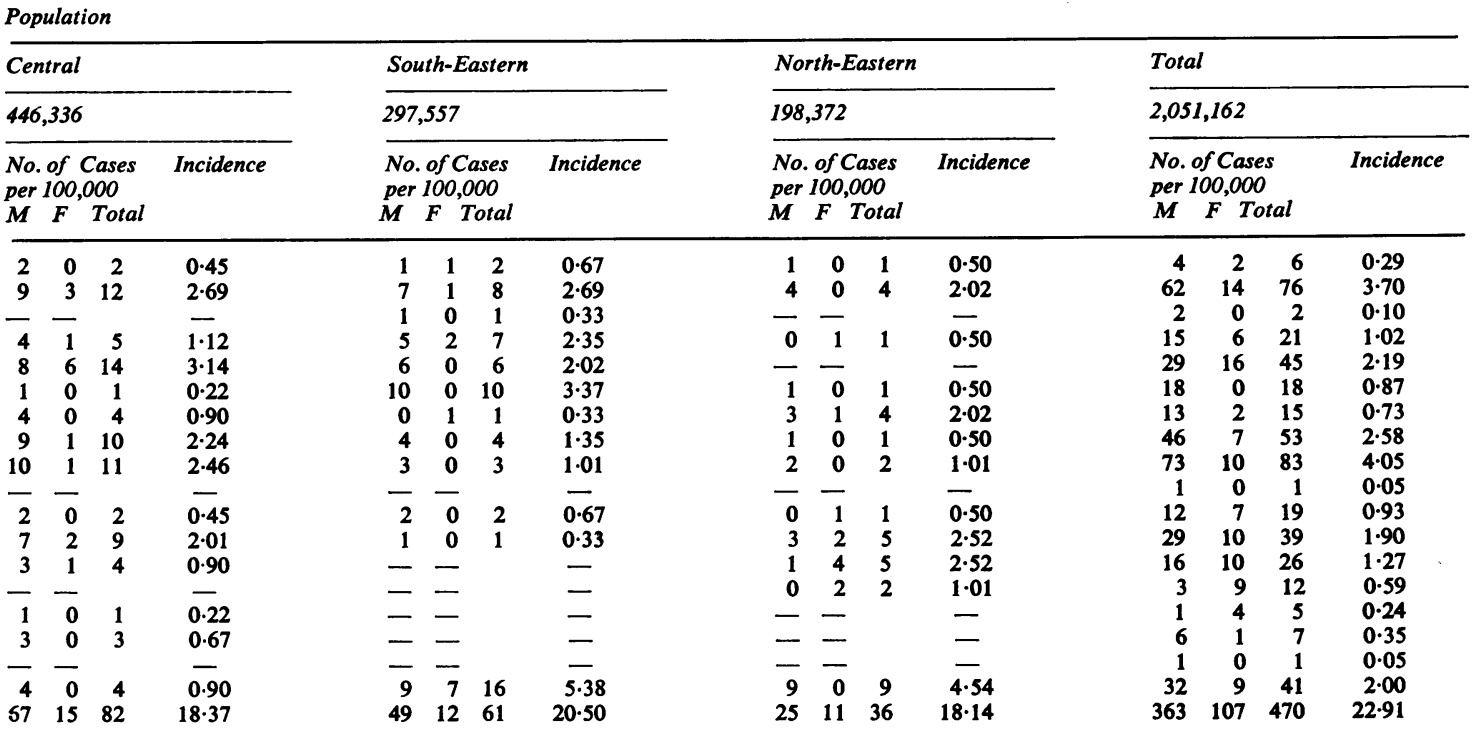

TABLE IV

OCCURRENCE-RATES FOR GASTROINTESTINAL MALIGNANT NEOPLASMS FOR SELECTED SITES BY SEX AND AGE GROUP IN 1960 TO 1964 IN RAILWAY POPULATION IN INDIA ${ }^{1}$

\begin{tabular}{|c|c|c|c|c|c|c|c|c|c|c|c|c|c|}
\hline \multirow{3}{*}{ Cancer } & \multicolumn{13}{|l|}{ Population } \\
\hline & \multicolumn{2}{|l|}{ All Ages } & \multicolumn{2}{|l|}{$18-24$} & \multicolumn{2}{|l|}{$25-34$} & \multicolumn{2}{|l|}{$35-44$} & \multicolumn{2}{|l|}{$45-54$} & \multicolumn{2}{|l|}{55} & \multirow{2}{*}{$\begin{array}{l}56-64 \\
F \\
44,313\end{array}$} \\
\hline & $\begin{array}{l}M \\
1,034,000\end{array}$ & $\begin{array}{l}F \\
1,017,162\end{array}$ & $\begin{array}{l}M \\
316,721\end{array}$ & $\begin{array}{l}F \\
297,990\end{array}$ & $\begin{array}{l}M \\
260,829\end{array}$ & $\begin{array}{l}F \\
245,404\end{array}$ & $\begin{array}{l}M \\
242,198\end{array}$ & $\begin{array}{l}F \\
227,874\end{array}$ & $\begin{array}{l}M \\
204,937\end{array}$ & $\begin{array}{l}F \\
192,817\end{array}$ & $\begin{array}{l}M \\
9,315\end{array}$ & $\begin{array}{l}F \\
8,764\end{array}$ & \\
\hline All sites & $35 \cdot 1$ & $10 \cdot 5$ & 1.9 & 0.6 & $13 \cdot 4$ & $15 \cdot 3$ & $52 \cdot 0$ & $27 \cdot 5$ & $86 \cdot 4$ & 14.0 & 96.0 & $34 \cdot 2$ & $67 \cdot 7$ \\
\hline Lip & 0.3 & 0.2 & - & - & - & 0.7 & 0.8 & 0.8 & 1.0 & - & - & - & - \\
\hline Tongue & 6.0 & 1.4 & 0.6 & - & $1 \cdot 2$ & $4 \cdot 4$ & $10 \cdot 3$ & $3 \cdot 1$ & $14 \cdot 2$ & 1.9 & $21 \cdot 5$ & - & $4 \cdot 5$ \\
\hline Mouth & $1 \cdot 5$ & 0.6 & - & - & 0.8 & - & $2 \cdot 5$ & 1.6 & $2 \cdot 0$ & - & 10.7 & - & 6.8 \\
\hline Cheek & $2 \cdot 8$ & 1.6 & 0.3 & - & $1 \cdot 5$ & $2 \cdot 2$ & $3 \cdot 3$ & $5 \cdot 5$ & $7 \cdot 3$ & $3 \cdot 7$ & - & - & $4 \cdot 5$ \\
\hline Tonsil & $1 \cdot 7$ & - & - & - & 0.4 & - & 3.7 & - & 3.9 & - & - & - & - \\
\hline Pharynx & $1 \cdot 3$ & 0.2 & - & 0.6 & - & - & $2 \cdot 1$ & - & 3.4 & - & $10 \cdot 7$ & - & $2 \cdot 3$ \\
\hline Oesophagus & $4 \cdot 4$ & 0.7 & - & - & $2 \cdot 3$ & 0.7 & $5 \cdot 4$ & 3.9 & $11 \cdot 2$ & 0.9 & $21 \cdot 5$ & - & - \\
\hline Stomach & $7 \cdot 1$ & 1.0 & - & - & 1.9 & - & $9 \cdot 1$ & $3 \cdot 1$ & $21 \cdot 5$ & 1.9. & - & - & $9 \cdot 0$ \\
\hline Liver & $1 \cdot 5$ & 1.0 & 0.3 & - & 0.4 & $2 \cdot 2$ & $1 \cdot 7$ & 1.6 & 3.9 & - & $21 \cdot 5$ & $11 \cdot 4$ & $11 \cdot 3$ \\
\hline Gall-bladder & 0.3 & 0.9 & - & - & - & - & - & $3 \cdot 1$ & $1 \cdot 5$ & 0.9 & - & $22 \cdot 8$ & $4 \cdot 5$ \\
\hline Pancreas & 0.6 & $0 \cdot 1$ & - & - & 0.8 & - & 0.4 & - & $1 \cdot 5$ & - & - & - & -- \\
\hline Rectum & $2 \cdot 8$ & 1.0 & - & - & 1.9 & 0.7 & $5 \cdot 8$ & $1 \cdot 6$ & $4 \cdot 4$ & 0.9 & - & - & 13.5 \\
\hline
\end{tabular}

${ }^{1}$ The rates given are per 100,000 population

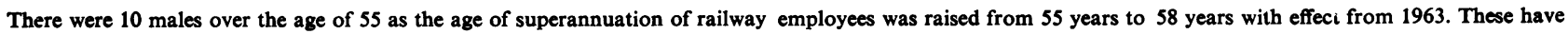
not been taken into account in this statement.

The females in age group 56 to 64 years are chiefly widowed mothers of the railway employees.

CANCER OF THE PANCREAS There were only eight cases recorded in this series and these were chiefly among the south Indians and the Deccanese, showing a high prevalence rate of this tumour among the south Indians as compared with that in the north Indians.

\section{DISCUSSION}

In this study an attempt has been made to determine the incidence rates of gastrointestinal cancers by identifying, as far as possible, every case of these tumours diagnosed between 1960 and 1964 among 
TABLE V

DISTRIBUTION BY AGE OF GASTROINTESTINAL CANCERS TREATED IN RAILWAY HOSPITALS ON VARIOUS ZONAL RAILWAYS IN INDIA IN 1960-1964'

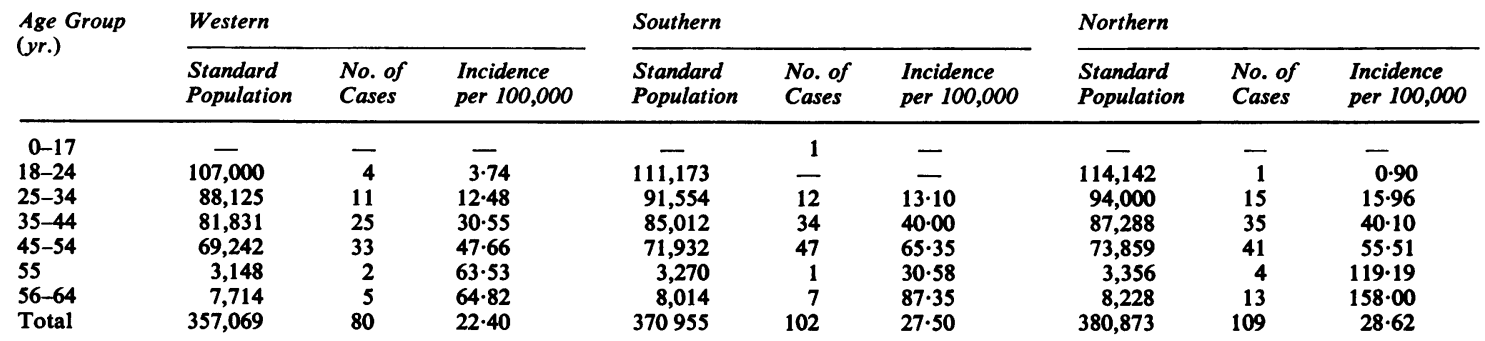

railwaymen in India and relating these to the population at risk. Even though our population is not entirely representative of the general population in the country for reasons already discussed, it is identical with regard to its constitution in the different geographical areas studied, and since it is derived from the general population between the ages of 18 and 55 years from various geographical areas, our data can provide an objective study of the geographical distribution of these cancers in the general population in the country, among adults between the ages of 18 and 55 years. Our results show that big differences exist in the prevalence of certain cancers, especially the cancers of the buccal cavity, the stomach and liver, and the colon, in various parts of the country.

The survey has necessarily been an indirect one and, therefore, it suffers from several defects. The most important of these is that such indirect surveys almost always result in underestimates of frequency. When one has to depend on case records for the number of sufferers in whom the diseases have been diagnosed, the possibility of failure to retrieve all records as one searches further back in time is ever present. Whilst this would affect the absolute numbers of cases, it would not invalidate the geographical comparisons between different zones. We tested this possibility by analysing the figures for 1964 only, as there would be less chance of missing case records pertaining to a recent and shorter period of time. This analysis confirmed the geographical trends noted in the main study.

Another drawback of the indirect method, if it covers a limited period of time, is that cases diagnosed later or cases misdiagnosed earlier as benign and in whom the diagnosis was corrected later, may be missed from the list. This can particularly affect the results of the survey if patients do not take treatment and resort to indigenous or home remedies. Due to easy accessibility of medical care, the special facilities for surgery and radiotherapy, and, above all the lethal and progressive course of the diseases unless treated adequately, it is unlikely that the proportion of patients who never sought medical help from the railway hospitals could be of significance. Moreover, this is not likely to vitiate the geographical comparisons, as it would equally affect the various units.

Since we are here acutely interested in the relative geographical variations in incidence rates and not so much in absolute numbers, we are justified in concluding that the trends we have noted are independent of the influence of these factors.

India is a vast country with extremes of temperature and humidity but we propose to discuss chiefly the dietary habits of the people, because, as pointed out by Acheson and Doll (1964), the main causes may perhaps be in the diet and eating habits.

\section{CAUSAL INFLUENCES}

CANCERS OF THE BUCCAL CAVITY AND OESOPHAGEAL CANCERS A causal association between betel chewing and the cancers of the buccal cavity has been suggested in several independent studies (Sanghvi, Rao, and Khanolker, 1955; Shanta and Krishnamurthi, 1963; Paymaster, 1964; Wahi, Kehar, and Lahari, 1966; Hirayama, 1966). Our data confirm the existence of an association between betel leaf chewing and all types of cancer of the mouth, anterior tongue, and palate. For example, in the Punjab, where the chewing of betel leaf is uncommon, the incidence of these cancers is infrequent, whereas in the adjacent state of Uttar Pradesh, where betel leaf chewing is very common, the incidence rates of these cancers are very high. A number of important aspects, however, remain to be clarified. It is still uncertain whether it is the betel leaf (Piper betel), or the tobacco, or some other component of the quid which is responsible for the effect. Many workers have shown the role of the tobacco to be an important factor (Khanolkar, 1945; Paymaster, 1964), whereas others feel that this association is weak and possibly overemphasized (Shanta and 
TABLE V-continued

DISTRIBUTION BY AGE OF GASTROINTESTINAL CANCERS TREATED IN RAILWAY HOSPITALS ON VARIOUS ZONAL RAILWAYS IN INDIA IN 1960-1964. ${ }^{1}$

\begin{tabular}{|c|c|c|c|c|c|c|c|c|c|c|c|}
\hline \multicolumn{3}{|l|}{ Central } & \multicolumn{3}{|c|}{ South-Eastern } & \multicolumn{3}{|c|}{ North-Eastern } & \multicolumn{3}{|l|}{ Total } \\
\hline $\begin{array}{l}\text { Standard } \\
\text { Population }\end{array}$ & $\begin{array}{c}\text { No. of } \\
\text { Cases }\end{array}$ & $\begin{array}{l}\text { Incidence } \\
\text { per } 100,000\end{array}$ & $\begin{array}{l}\text { Standard } \\
\text { Population }\end{array}$ & $\begin{array}{l}\text { No. of } \\
\text { Cases }\end{array}$ & $\begin{array}{l}\text { Incidence } \\
\text { per } 100,000\end{array}$ & $\begin{array}{l}\text { Standard } \\
\text { Population }\end{array}$ & $\begin{array}{l}\text { No. of } \\
\text { Cases }\end{array}$ & $\begin{array}{l}\text { Incidence } \\
\text { per } 100,000\end{array}$ & $\begin{array}{l}\text { Standard } \\
\text { Population }\end{array}$ & $\begin{array}{l}\text { No. of } \\
\text { Cases } \\
\text { (all cancer }\end{array}$ & $\begin{array}{l}\text { Incide } \\
\text { per } 10 \\
\text { rs) }\end{array}$ \\
\hline- & - & - & - & 1 & - & - & - & - & - & 2 & - \\
\hline 133,762 & - & - & 89,175 & 2 & $2 \cdot 24$ & 59,450 & - & - & 614,711 & 7 & $1 \cdot 14$ \\
\hline 110,157 & 11 & 9.98 & 73,438 & 3 & 4.08 & 48,959 & 4 & $8 \cdot 17$ & 506,233 & 56 & $11 \cdot 62$ \\
\hline 102,289 & 28 & $27 \cdot 37$ & 68,192 & 28 & $41 \cdot 06$ & 45,460 & 11 & $24 \cdot 11$ & 470,072 & 161 & $34 \cdot 25$ \\
\hline 86,551 & 32 & 36.97 & 57,702 & 25 & $43 \cdot 33$ & 38,468 & 14 & $36 \cdot 39$ & 397,754 & 192 & $48 \cdot 27$ \\
\hline 3,934 & 5 & $126 \cdot 45$ & 2,622 & - & - & 1,749 & - & - & 18,079 & 12 & $66 \cdot 38$ \\
\hline 9,643 & 6 & $62 \cdot 22$ & 6,428 & 2 & $31 \cdot 11$ & 4,286 & 7 & 16332 & 44,313 & 40 & $90 \cdot 27$ \\
\hline 446,336 & 82 & $18 \cdot 37$ & 297,557 & 61 & $20 \cdot 50$ & 198,372 & 36 & $18 \cdot 14$ & $2,051,162$ & 470 & 22.91 \\
\hline
\end{tabular}

${ }^{1}$ Standard population of Segi (1964) has been used to determine the population at risk in various age-groups.

Krishnamurthi, 1963; Hirayama, 1966). Wahi et al. (1966) have produced evidence, in their study from Agra (U.P.), of an association with a particular type of tobacco. Our data show that the incidence of the buccal and oesophageal cancers is comparatively less in south India as compared with the Rajasthan and U.P. areas of the north, although the habit of tobacco chewing is as, or even more, prominent in the south than in the north. In the south of the country, cancers of the buccal cavity are relatively more frequent in Kerala, Madras, and Hyderabad, although the habit of chewing tobacco, is in fact highly prevalent in Madras, Bangalore, Mangalore, and some parts of the Mysore State in south India. In certain districts of the west coast, although small bits of a partially dried leaf of tobacco are rolled up into small quids and a person will go on chewing these throughout the day with or without the betel leaf, these cancers are rare in these areas. Similarly, in the Haryana region of the Punjab, and in Saurashtra where the incidence of these cancers is very low, quid forms an important component of the betel leaf. Tobacco chewing can-

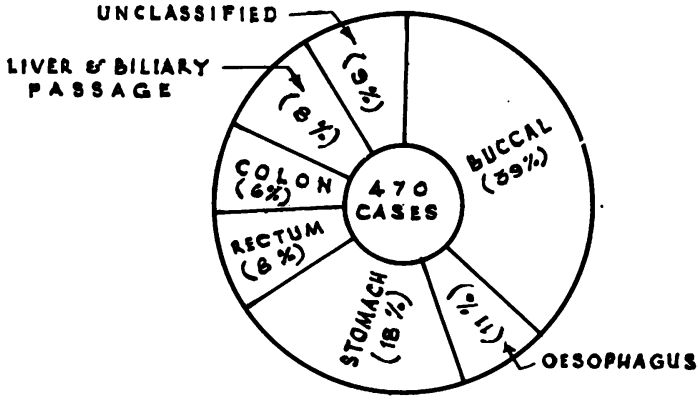

FIG. 3. Relationship between incidence-rates expressed as der 100,000 of the total number of employees at risk, for gastric, liver, and colon cancers on different railway zones. not, therefore, account for these differences, because even though quid is an important ingredient of the betel leaf used in Mangalore, the Haryana region of the Punjab, and the Saurashtra regions, the incidence rates of these cancers are low in these areas.

Chewing of betel nut and betel leaf, commonly known as paan, is a universal habit in India and the differences in the paans eaten in the various parts of the country have been described in an earlier communication (Malhotra, 1964). Two ingredients of the paan have as yet received insufficient attention, namely, the slaked lime solution, which is highly alkaline with a $p \mathrm{H}$ of 11.4 to 12.4 , and Kattha (catechew) solution which has a $p \mathrm{H}$ of 3.2 to 4.2 depending upon the concentrations used. Important differences in the use of these ingredients exist in different regions. In U.P., Rajasthan, and Hyderabad, a concentrated solution of slaked lime is liberally smeared over the leaf in a thick layer, followed by a lighter application of a weak solution of kattha (catechew). In Kerala (south India) where oropharyngeal cancers are comparatively more common than in the rest of the south, although the use of slaked lime is highly prevalent, kattha is hardly used. In fact, in certain parts of Kerala the only ingredients of the paan are the betel leaf, raw arica nut, and a liberal spread of a highly alkaline, thick slaked lime paste. In Kerala in the south and Assam in the east, in addition to the slaked lime applied to the betel leaf, a concentrated paste of slaked lime is made in the form of a miniature lollypop, which is dabbed on the tongue or is kept far back between the cheek and the teeth from where it is gradually sucked. In U.P., in the north, lime in addition to its application to the leaf is also added to the quid or it is placed in the mouth in small bits of a semisolid, dried paste of shell lime.

In the Punjab (Haryana), Saurashtra, and parts of south India, such as Mangalore and Bangalore, 
very little lime is used. Thus, in the Punjab and the Saurashtra the practice is just the reverse, and the betel leaf is first smeared with a highly concentrated solution of the acidic kattha, and only a weak solution of lime, which is applied in very small quantities to one corner of the leaf. In regions of the south comprising Bangalore and Mangalore, where the incidence of these cancers is low, the paan is composed of the betel leaf, roasted arica nut, and grated coconut but hardly any lime.

Thus, one striking difference in the paans of areas with higher incidence rates of oropharyngeal cancers, as compared with those with lower rates, is the liberal use of a highly alkaline solution of lime. On the other hand, in the Punjab, Saurashtra, and certain parts of south India, such as Bangalore and Mangalore, where the incidence of these cancers is low, very little lime is used, and an acidic solution of kattha is liberally applied to the betel leaf. From this it is clear that the U.P., Rajasthan, and Kerala paans are highly alkaline in their reaction, whereas the Punjabi and the Saurashtra paans are, in fact, acidic in reaction. The data of Hirayama (1966), suggesting infrequency of cancer in Kabul (Afghanistan) and Nigeria, where people chew tobacco without lime, and the high frequency or oral cancer in New Guinea, where betel nut and lime are chewed without tobacco, are in consonance with our findings and strongly support the causal association of the use of lime with these malignancies. The mode of action of lime is, however, less clear and, therefore, its importance as a factor of aetiological importance has been overshadowed by the quid theory.

The highly alkaline reaction of the paans, in areas where oropharyngeal cancers are common, provides support to the role of lime as an aetiological factor. In an alkaline reaction, the intracellular mucus of the mucous cells is rendered fluid and is removed from the cell (Ball and James, 1961), thus producing inflammatory and proliferative changes in the mucosa. An important clue to the probable mode of action of lime is provided by the experimental work of Lawson (1964), who has uniquivocally demonstrated that the alkaline duodenal contents when led into the stomach either by reflux or directly, caused superficial gastritis, atrophic gastritis, and epithelial proliferation with a striking increase in mitotic activity of the order of 40 -fold. It is, therefore, reasonable to suggest that a similar situation produced by the highly alkaline paans of the U.P., Rajasthan, and Kerala may bear responsibility for similar proliferative changes in the oral mucous membrane. There is an urgent need to explore further these geographical patterns of paans and these cancers, while at the same time to test experimentally the similarity in the response of the epithelial cells of the oropharyngeal mucosa to an alkaline milieu with the response of gastric mucous membrane. It is, however, necessary to remember that mucus is dissolved by alkalis and precipitated by acids, and if it forms an integral part of the mucous cells, its removal will result in repeated trauma leading to the proliferative and hyperplastic changes described by Lawson (1964). Because hyperplasia of long duration is often a prelude to neoplasia, this can explain the close association of these cancers with the use of the highly alkaline solution of slaked lime in the betel leaf. The liberal use of the aciditic kattha solution in the Punjab and Saurashtra, on the other hand, will by virtue of its acidic $p \mathrm{H}$ and also its highly astringent properties, precipitate the mucus of the mucous cells and thus prevent it from escaping from the epithelium, and, therefore, may in fact have a protective role.

Two other differences in the ingredients of the paan are worth mentioning. The paan eaten in the Punjab and Saurashtra usually contains a piece of clove (Syzigium aromaticum), a small quantity of coarsely powdered liquorice, one or two pieces of cardamoms, and a small quantity of dried aniseeds in addition to the hard betel nut and catechew. Chewing of paans containing these increases the flow of mucus in the saliva (Malhotra, 1964). In fact, clove oil has been found to be the most effective stimulant of mucus from the mucous glands (Hollander and Lanber, 1948).

As another test of the causal relationship of betel leaf containing lime, if we examine the habitual sites where the paan is kept in the mouth, we find that the practice in Kerala and Hyderabad is to keep it between the teeth and the cheek so that it is more in contact with the cheek and the gums than the tongue, whereas in U.P. and Rajasthan the paan is habitually put between the teeth or in the cavity of the mouth, so that the tongue is more in contact with the alkaline milieu of the paan. This may explain why cancer of the cheek is more common in Kerala and Hyderabad and cancer of the anterior tongue more common in Rajasthan and U.P., and thus further support the causal influence of lime in these cancers.

In epidemiological studies of this type, therefore, to get the true picture of aetiological factors, it is necessary not only to establish the existence of an association with betel chewing but also to explore the ways the paans are prepared and eaten because in one case, by virtue of its ingredients, the acidic reaction of the paan may not only prevent the mucus of the mucous cells from escaping, but may in fact, stimulate the protective layer of surface mucus; while in the other, by virtue of its alkaline reaction, it may 'damage' the epithelium by removing the 
intracellular mucus, and thus cause proliferative changes in the epithelial cells, with a striking increase in mitotic activity.

GASTRIC CANCER Big differences in the incidence of gastric cancers are present between the north and the south of the country, there being four times as many cases in the southern zone compared with the northern (Fig. 2 and Table III). Sex distribution also shows interesting differences. Thus, whilst in the south, where the incidence of gastric cancer is the highest in the country, the male-female ratio was $20: 1$, it is reduced to $3: 2$ for U.P. and $1: 1$ for Maharashtra (Bombay). It is difficult to explain these sex variations on the basis of any immunity of the female sex to this cancer, and environmental factors are obviously at work. Many studies have been concerned with the aetiology of the cancer of the stomach and several diverse causes have been suggested. Acheson and Doll (1964), however, have shown that of the environmental factors the main causes may perhaps be found in the diet. The working party of the World Organization of Gastroenterology (World Organization of Gastroenterology, 1964) have emphasized the notable rarity of gastric cancers in areas in which maize provides the staple food; and in direct contrast to this, the disease is believed to be common in nearly all areas where potatoes provide the principal source of energy.

We have no accurate data with regard to maize consumption and a lower frequency of gastric cancers but the high incidence of these cancers among the South Indians does not support the thesis on potatoes, because in south India where these cancers are common the principal source of energy is boiled rice, ragi (Eulicine coracona), or tapioca and not potatoes (Malhotra, 1964; Indian Council for Medical Research, 1964).

CANCER OF THE LIVER AND GALL BLADDER In direct contrast to gastric cancer is the distribution of cancers of the liver and the gall bladder (Table III and Fig. 4). While gastric cancer is common among the south Indians and rare among the north Indians, especially the Punjabis, the distribution of the primary cancers of the liver and gall bladder is just the reverse. In fact, liver and gall bladder cancers are the most frequently observed cancers in the north contributing to $21 \%$ of a total of 109 cases of all gastrointestinal cancers in the northern zone (Table III), whilst cancer of the stomach is hardly ever seen, especially in the Punjabis in the north. Thus, cancers of the liver and gall bladder are 12 times more frequent in the north as compared with the south, the respective incidence rates being 6 per 100,000 in the northern zone and only 0.5 per 100,000 in the southern zone (Table I). This striking peculiarity makes one suspect that factors which promote the development of the one may prevent the development of the other. Looking into the relative frequencies of peptic ulcer and cholelithiasis from the operation registers of the Delhi Hospital in the north and the Madras Hospital in the south, we were impressed by the remarkable differences in the distribution of these diseases too: whilst peptic ulcer is very common in the south and rare in the Punjab (north) (Malhotra, 1964), cholelithiasis is common in the Punjab and rare in the south of India. It is tempting to suppose that a common factor may be involved in the production of the cancers of the stomach and biliary system, which by virtue of its presence causes one, and by virtue of its absence, the other.

Notable differences in the excretion of faecal urobilinogen have been observed between the south Indians as compared with the north Indians (Malhotra, 1966a): the mean values for faecal urobilinogen excretion were three and a half times lower in the north Indian males than the south Indians, and twice as low in women as in men, the figures in men being $64.4 \mathrm{mg} . \%$ and $19.8 \mathrm{mg} . \%$ respectively for south India as compared with north India, whilst in women the average levels were $35.1 \mathrm{mg} . \%$ and $12.3 \mathrm{mg} . \%$ (Malhotra, 1966a). In feeding experiments, we have observed that the faecal urobilinogen excretion was increased four-fold when north Indians, habituated to a masticatory Punjabi diet, were fed on the sloppy boiled rice and lentil soups of south India (Malhotra, 1966b), the respective mean values being $19.8 \mathrm{mg} . \%$ on a wheat

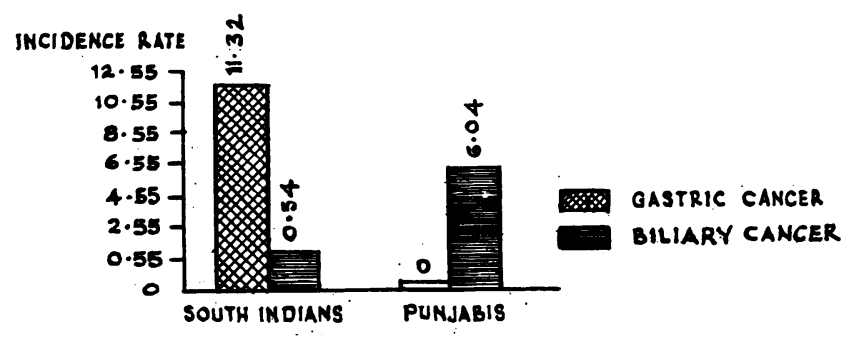

FIG. 4. Comparison between the incidencerates, expressed as 100,000 of total employees, for gastric cancer versus biliary cancer among the South Indians and the Punjabis. 
diet and $71.6 \mathrm{mg} . \%$ on a rice diet $(\mathrm{P}<0.001 ; \mathrm{n}=27)$ for concentration and $53 \mathrm{mg}$. $/ 24$ hours for a wheat diet and $99 \mathrm{mg} . / 24$ hours for a rice diet for total excretion $(\mathrm{P}<0.001 ; \mathrm{n}=27)$. A possible explanation for this might be that the mucus concentration in the saliva rises with masticatory meals as compared with sloppy diets (Dewar and Parfitt, 1954; Malhotra, $1967 \mathrm{~b}$ ), and, since mucus is precipitated by strong acid in the stomach, and in this state might be less permeable to stimuli which are responsible for CCK release, which are thus prevented from reaching the receptors (Malhotra, 1966b). Since the amount of faecal urobilinogen excreted depends upon the amount of bile entering the intestinal lumen (Varley, 1962), these results have been interpreted to mean that these dietetic variations produce big changes in the contraction of the gall bladder as well as in the flow rate of bile. With a decrease in the gall bladder contraction, bile will be held longer in the gall bladder and the biliary system.

The derivatives of cholic acid are amongst the most powerful of chemical carcinogens (Wieland and Dane, 1933; Cook and Haslewood, 1933). Their mode of carcinogenesis is, however, totally unclear, but it is tempting to speculate whether the stasis of bile in the biliary system and the liver, caused by the pattern of diet and eating, could lead to the more frequent development of cancers of the liver or gall bladder in the north Indians compared with the south Indians, possibly by removing the fat globules in the liver cells and thus interfering with the cell metabolism.

This effect of the pattern of diet and eating, leading to an increase in the flow rate of bile when south Indian sloppy diets are eaten, is of significance in view of the evidence presented by Spira (1956), Lawson (1964), and Du Plessis (1965) that duodenal reflux of bile into the stomach can set up chronic gastritis. The definite experimental evidence of a 40 -fold increase in the mitotic activity of the epithelial cells and the marked proliferative changes in the mucosa of the stomach, as a result of duodenal reflux of bile into the stomach noted by Lawson (1964), can explain the higher occurrence rates of gastric cancers in the south Indians whose 'sloppy' diets promote greater flow rates of bile as compared with the north Indians. This may explain the peculiar association of higher gastric cancer frequencies with lower occurrence rates of hepatoma, and the association of higher hepatoma frequencies with lower occurrence rates of gastric cancers.

The incidence of gastric cancers is rapidly declining in many countries, particularly the U.S.A., Norway, and the Netherlands. Further studies are urgently needed to investigate whether with this decline in gastric cancer there has been a concomitant increase in the cancers of the liver and gall bladder in these countries, as would seem to be suggested by this hypothesis. At least three recent reports from England and the U.S.A. show that there appears to have been an increase in the incidence of primary carcinoma of the liver (Elkington, McBrien, and Spencer, 1963; MacDonald, 1956, 1957; Patton and Horn, 1964) at the same time as there has been a decrease in cancer of the stomach. This contrast in the occurrence rates of these two tumours is also well seen in the necropsy data of Steiner (1954), because while the Afro-American had lost the high frequency of primary carcinoma of the liver that prevails in many native Africans, he had simultaneously acquired gastric cancer in the high frequency that prevailed in the United States. This increase in hepatoma rates, taken along with a decrease in the incidence of gastric cancers in these countries, supports the hypothesis advanced in this paper that cancers of the stomach and liver have a common pathogenesis because there are certain factors in the pattern of diet and eating, possibly connected with the flow rates of bile, which, by their presence, promote the development of the one and prevent the development of the other.

CANCER OF THE COLON A suspicion seems to have been established that in western countries in areas where gastric cancer rates are high colon cancer rates are low and vice versa (Jones, 1966). The picture in the present study does not conform with western experience, and we have found that both gastric and colon cancers are common in the south of India and both are rare in the north. In Steiner's (1954) necropsy data also there was no great contrast between the incidence rates of gastric and colon cancers, gastric cancers being the commonest and colon cancers the third commonest cancers in his series.

One explanation that might be likely is the differences in the cellulose and fibre content in the diets of south Indians as compared with those of north Indians. While the north Indian diets are rich in roughage, cellulose, and vegetable fibres, these are almost completely lacking in the south Indian diets. We have investigated this point further by the examination of faeces in these disparate groups, which showed that whilst vegetable fibres were abundant in the stools of north Indians these were completely absent in those of the south Indians. This may have important implications because of the recent evidence of Popják, French, and Folley (1951) that the fermentation of cellulose and vegetable fibres in the intestines gives rise to large quantities of acetic acid which may thus act in a protective manner on the intracellular mucus of the mucous membrane of 
the colon by virtue of its acid milieu in north Indians while giving no such protection to the south Indians.

The data presented in this paper support the thesis that environmental factors play an important part in the development of these cancers, and that perhaps many of them are dietary and therefore possibly within the realm of prevention. While it may not always be easy to disentangle from the thicket of the environment factors which relate with certainty to causation, it is probable that the relationship between the alkaline milieu created by environmental factors upon the intracellular mucus of the mucous cells of the epithelium, whether they are in the oropharynx or in the stomach or even in the bronchial tree (Malhotra, 1967b) or the cervix uteri, may provide a working hypothesis for the pathogenesis of malignant disease affecting mucous membranes bearing mucous cells. This concept demands further investigation.

\section{SUMMARY AND CONCLUSIONS}

This report gives an analysis of $\mathbf{4 7 0}$ cases of gastrointestinal cancers seen among the railway populations in various parts of India over the five-year period 1960-1964. Oropharyngeal cancers form $39 \%$ of the total and show a geographical distribution which confirms the association with betel chewing, but does not support the thesis that tobacco leaf is the causative agent. There is, on the other hand, a close correlation with the consumption of lime in the betel leaf and the distribution of these cancers, which seems to indicate that use of slaked lime in the paan probably acts by damaging the mucous cells of the epithelium by virtue of its highly alkaline reaction (pH 12.4). It may cause epithelial proliferation with an increase in mitotic activity, akin to that described by Lawson (1964) in the case of gastric epithelium.

Gastric cancers are common in the south of India and rare in the north, but the primary cancers of the liver and gall bladder are common in the north and rare in the south. This association of higher gastric cancer rates with lower hepatoma rates in one area, and the inverse association of higher hepatoma rates and lower gastric cancer rates in another, suggests that in the development of these diverse tumours there may be common aetiological factors, most of which are dietary. The pattern of diet and eating influences the flow rates of bile, and the possible role of the flow rates of bile in the pathogenesis of gastric cancers, on the one hand, and hepatoma and cancer of the gall bladder on the other, is discussed. The striking sex disparities in the distribution of gastric cancers in different geographical areas make it unlikely that females enjoy any protection. These, on the other hand, make for environmental factors in the causation of this cancer, which may be mainly in the pattern of diet and eating. The geographical differences in the incidence rates of cancer of the colon also appear to be related to dietary factors.

A view is advanced that malignant disease involving mucous membranes may be the result of chronic interaction of an abnormal alkaline milieu on the intracellular mucus of the mucous cells of epithelium.

I am deeply indebted to my colleagues, the chief medical officers of the Indian railways, especially Dr. P. A. Menon, F.R.C.S.; Dr. T. J. Cherian, M.D., F.A.C.S.; Dr. S. K. Bose, M.B., D.P.H.; Dr. J. R. Gadeock, M.D., M.P.H.; Dr. R. C. Vevaina, M.B., Ch.B., M.R.C.S., D.P.H.; Dr. A. Ram Das, M.S., D.P.H., and several district medical officers of the Indian railways who have helped in the collection of the clinical data, without which this study could not have been possible.

\section{REFERENCES}

Acheson, E. D., and Doll, R. (1964). Dietary factors in carcinoma of the stomach: a study of 100 cases and 200 controls. Gut, 5, 126-131.

Ball, P. A. J., and James, A. H. (1961). The histological background to gastric ulcer. Lancet, 1, 1365-1367.

British Medical Journal (1966). Cancer and the immigrant. Brit. med. J., 1, 307-309.

Cook, J. W., and Haslewood, G. A. D. (1933). The conversion of a bile acid into a hydrocarbon derived from 1 :2-benzanthracene. Chemy Ind., 52, 758. Cited by Clayson, D. B. (1962). Chemical Carcinogenesis, p. 343. Churchill, London.

Dewar, M. R., and Parfitt, G. J. (1954). An investigation of the physical properties of saliva and their relationship to the mucin content. J. dent. Res., 33, 596-605.

Du Plessis, D. J. (1965). Pathogenesis of gastric ulceration. Lancet, 1, 974-978.

Elkington, S. G., McBrien, D. J., and Spencer, H. (1963). Hepatoma in cirrhosis. Brit. med. J., 2, 1501-1503.

Haenszel, W. (1961). Cancer mortality among the foreign-born in the United States. J. nat. Cancer Inst., 26, 37-132. Cited in Brit. med. J. (1966). 1, 307-309.

Hirayama, T. (1966). An epidemiological study of oral and pharyngeal $\mathbf{L}=$ pharyngeal cancer in central and South-East Asia. Bull. Wld Hlth Org., 34, 41-69.

Hollander, F., and Lanber, F. U. (1948). Eugenol as a stimulus for gastric mucous secretion. Proc. Soc. exp. Biol. (N.Y.), 67, 34-37. Cited by A. H. James (1957). The Physiology of Gastric Digestion, p. 133. Arnold, London.

Indian Council of Medical Research (1964). Diet Atlas of India. Spec. Rep. Ser., No. 48.

Jones, F. A. (1966). Epidemiology of gastrointestinal cancer. Paper presented at the 7th Annual Conference of the Indian Society of Gastroenterology, Bombay.

Khanolkar, V. R. (1945). The susceptibility of Indians to cancer. Indian J. med. Res., 33, 299-314.

Lawson, H. H. (1964). Effect of duodenal contents on the gastric mucosa under experimental conditions. Lancet, 1, 469-472.

MacDonald, R. A. (1956). Cirrhosis and primary carcinoma of the : liver. New Engl. J. Med., 255, 1179-1183.

- (1957). Primary carcinoma of the liver: a clinicopathologic study of one hundred and eight cases. Arch. intern. Med., 99, 226-279.

Malhotra, S. L. (1964). Peptic ulcer in India and its aetiolcgy. Gut, 5, $412-416$.

- (1966). Effect of diet and antacids in gall-bladder contraction. Proc. 3rd wld. Congr. Gastroent., Tokyo. 2, 106. 
Malhotra, S.L. (1967a). Study of the effect of saliva on the concentration of mucin in gastric juice and its possible relationship to the aetiology of peptic ulcer. Gut, in the press.

- (1967b). Some clues to the pathogenesis of lung cancer. To be published.

Patton, R. B., and Horn, R. C., Jr. (1964). Primary liver carcinoma. Autopsy study of 60 cases. Cancer (Philad.), 17, 757-768.

Paymaster, J. C. (1964). Cancer and its distribution in India. Ibid., 17, 1026-1034.

Popják, G., French, T. H., and Folley, S. J. (1951). Utilisation of acetate for milk-fat synthesis in the lactating goat. Biochem. J., 48, 411-416.

Sanghvi, L. D., Rao, K. C. M., and Khanolkar, V. R. (1955). Smoking and chewing of tobacco in relation to cancer of the upper alimentary tract. Brit. med. J., 1, 1111-1114.

Segi, M., and Kurihara (1964). Age-adjusted Death Rates for Malignant Neoplasms for Selected Sites, by Sex in 24 Countries. Department of Public Health, Tokaku University School of Medicines, Sendai.

Shanta, V., and Krishnamurthi, S. (1963). Further study in aetiology of carcinomas of the upper alimentary tract. Brit. J. Cancer, 17, 8-23. Cited by Hirayama (1966).

Spira, J. J. (1956). Gastro-Duodenal Ulcer. Butterworth, London.

Steiner, P. E. (1954). Cancer: Race and Geography, pp. 6-7. Williams and Wilkins, Baltimore.

Varley, H. (1962). Practical Clinical Biochemistry, 3rd ed., pp. 296-297. Heinemann, London.

Wahi, P. N., Kehar, U., and Lahiri, B. (1965). Factors influencing oral and oropharyngeal cancers in India. Brit. J. Cancer, 19, 642-660.

Wieland, H., and Dane, E. (1933). Untersuchungen über die Konstitution der Gallensäuren. LII. Mitteilung über die Haftstelle der Seitenkette. Hoppe-Seylers Z. physiol. Chem., 219, 240. Cited by Clayson, D. B. (1962). Chemical Carcinogenesis, p. 346. Churchill, London.

World Health Organisation (1957). Manual of the International Statistical Classification of Diseases, Injuries, and Causes of Death. W.H.O., Geneva.

World Organization of Gastro-enterology (1964). The epidemiology of gastrointestinal cancer with special reference to causation. Gut, 5, 196-200. 